\title{
A Fuzzy Information Evaluation Model for Scientific Innovation of Art Talents in Colleges
}

\author{
https://doi.org/10.3991/ijet.v15i12.14529 \\ Fanwen Kong \\ Shandong University (Weihai) Art College, Weihai, China \\ kongfw123@126.com
}

\begin{abstract}
In most colleges, the current scientific innovation model for art talents is not well implemented. Besides, it is a complex task to evaluate the effect of the said model. To solve the problems, this paper attempts to renovate the scientific innovation model for art talent in colleges. Firstly, the authors identified the problems in the current scientific innovation model for art talent training in colleges, and put forward several countermeasures. To evaluate the scientific innovation model, the performance indicators were selected and weighted based on analytical hierarchy analysis (AHP). Next, a fuzzy information evaluation model was established based on the weighted indicators. The research results provide strong supports to the scientific innovation of art talents in colleges.
\end{abstract}

Keywords-Art talents, scientific innovation model, analytical hierarchy analysis (AHP), fuzzy information evaluation model

\section{$1 \quad$ Introduction}

It's well known that science and technology are the primary productive forces, and scientific innovation is the main reflection of national competitiveness and also the key driving force for social development and. To promote national progress more attention must be paid to the scientific innovation capabilities of college students [13]. Today's higher education is quality-oriented, focusing on improving the comprehensive quality of college students. For this reason, the cultivation of art talents has gradually become an important part of higher education. In particular, with the continuous development of modern science and technology, scientific innovation has gradually played an important role in diversifying the cultivation mode of college art students. This can not only deepen the students' understanding and cognition of specialized art knowledge, but also better cultivate their artistic innovation ability and comprehensive quality, thus promoting the cultivation of high-level creative art talents in colleges [4, 5]. In this context, more and more scholars have carried out relevant research on the scientific innovation model of art talents, in order to improve their artistic innovation ability and comprehensive quality. From the perspective of art and design pedagogy, R. Keith Sawyer explored the way of achieving students' creative learning results from failures [6]. Zeng studied how to closely integrate humani- 
ties and arts with science and technology in the cultivation of innovative talents, and also analyzed related strategies [7]. Yong probed into the relationship between scientific innovation and artistic aesthetics, and declared that technological progress and artistic development are always closely related [8]. Lu analyzed the training of art talents through scientific innovation in colleges, and explored the training mode of talents in the Chinese art industry [9]. Cong et al. performed analysis for the combination of science and art by taking college students' science innovation as a case [10]. Rasidah Mahdi et al. studied the innovation participation and ability training in science and technology education through specific application cases [11].

The current research on the scientific innovation model of art students in colleges has achieved some research results, and promoted the implementation of this model, but lacking specific strategy support. Especially, with the continuous development of modern society, some new social needs and technology also affect the implementation effect of the scientific innovation model for art students in colleges. Moreover, the quantitative analysis for the implementation effect of this model still needs to be further deepened, although there are currently some methods of performance analysis [12-15], and each has a corresponding scope of application. Based on existing research results, this paper attempts to explore the implementation strategies of the scientific innovation model for art students in colleges. To evaluate the performance of the scientific innovation model, a fuzzy information evaluation model was established based on the AHP and fuzzy information. This paper consists of five parts. The first part summarizes and analyzes the current status for the implementation of the scientific innovation model for art students in colleges; the second part identifies the existing problems of this model; the third part analyzes the implementation strategies; the fourth evaluates the performance of the said model for art talents in colleges; the fifth part gives the conclusions.

\section{Existing Problems in the Scientific Innovation Model of Art Students in Colleges}

\subsection{The unclear orientation of scientific innovation}

Quality education is the pursuing goal of current higher education. In addition to their professional literacy and artistic temperament, the cultivation of art students must also focus on the comprehensive ability. Especially with the rapid development of modern science and technology, it has been the top priority to cultivate the comprehensive quality art talents with the characteristics of the times. The implementation of scientific innovation activities for art students is conducive to improving their comprehensive quality. However, this often lacks clear training goals. Many scientific innovation activities only pursue the significance of the form, while ignoring the essence of the implementation, which leads to the phenomenon of unclear positioning of scientific innovation for art students. It is mainly reflected in two aspects: on one hand, the aim of the scientific innovation activities isn't properly formulated by the organizers, and also due to various themes of activities, there may exist the art forms 
or expressions that are very disjointed with development of times, losing the significance of implementing the scientific innovation activities; on the other hand, when college art students participate in scientific innovation activities, they have too strong a utilitarian psychology, and blindly pursue scientific awards, which reveals the lack of regularity and logic in the art talent training. Thus, they ignore the essential issue in the training of college art talents, i.e., cultivating their innovative ability and practical ability.

\subsection{Single form of scientific innovation}

At present, the competition is the mainstream form of scientific innovation activities for art students, that is, the artistic works or products within the scope of certain artistic themes are created, and then rated through expert review. On one hand, this method has good operability in application form, and can also select some excellent works and train some high-quality art college students; on this other hand, such single form often leads to the phenomenon that many art college students only prepare, design and create works for specific scientific activity topics. Although the created works may be exquisite in one aspect, it restricts the creative perspective, the expandability, and the integration of the creative field of art college students, making it impossible to improve their comprehensive quality. The authors believes that the development of multi-form scientific innovation activities, such as art education and training activities, art knowledge popularization activities, art talent exchange academic conferences, and art industry-university-research integration promotion, etc., are all effective supplements to this single form, which can promote the cultivation of art professional ability and professional literacy from different perspectives and levels, and be more conducive to improving the comprehensive quality of college students.

\subsection{Insufficient guidance of scientific innovation}

Insufficient guidance for art college students is a common problem in the current implementation process of scientific innovation activities, and also a key issue affecting their implementation effects. It is mainly reflected in two aspects. First, the leaders of colleges, administrative departments or institutions do not pay much attention to the scientific innovation of art students. Many colleges have not systematically and scientifically formulated the implementation or participation plan of scientific innovation activities for art students, and not developed the related management system. Also, there are often no complete hardware facilities and software configurations for the development of scientific innovation activities, that is, the investment of colleges in terms of manpower, material and financial resources is such inadequate that the basic guarantees cannot be provided to support the implementation of scientific innovation model for college art students. The second is the lack of emphasis on scientific guidance. In colleges, many instructors of scientific innovation are often temporarily assigned according to the theme of activities, and are not sustainable. These instructors may have very strong professional ability, but they do not necessarily have ad- 
vantages in specific guidance links, which leads to a decline in the guidance of scientific innovation. Meanwhile, due to the temporality of such assignment, these instructors will often treat it as a side job, and cannot fully or mainly focus on the guidance of scientific innovation, which also affects the implementation effect of the art students' scientific innovation.

\subsection{Low participation of art students in scientific innovation}

At present, there are many competitions on scientific innovation activities for art students in colleges, including international, national, or provincial science competitions, and some scientific innovation activities undertaken by social institutions. The level and number of awards in the scientific competitions have become powerful means to enhance reputation of colleges, and important indicators for their education level. For this, many colleges have adopted various means to encourage or reward college students for participating in scientific innovation activities. Some even associate the achievements of these activities with the credits of college students and their continuing education. However, on the whole, the participation of college students is not high, especially the art students. Their participation is lower than that of engineering college students. This is because the creation of art works is a process of gradual design and innovation. It requires art students to have a solid theoretical knowledge reserve and strong artistic creation practice ability when they are creating art works. But for most art students, their professional knowledge reserves are not enough for them to complete scientific projects involving multi-fields and multi-disciplines. In addition, although they can conduct in-depth exploration in this area through the guidance of instructors or complete the creation of personal art works through individual effort, their study time and energy are often occupied, and most participants will not be able to win a prize or acquire the expected awards due to the limited number of awards. Especially when the awards and rankings have a great impact on the academic performance of college students, many students will feel that the contribution to scientific innovation activity is not proportional to the gains, and then lose the enthusiasm for such activity.

\section{$3 \quad$ Analysis on the Implementation Strategy of Scientific Innovation for Art Talents in Colleges}

\subsection{Using multiple innovation platforms as supports to further guarantee the scientific innovation effect of art talents in colleges}

In order to effectively enhance the implementation effect of scientific innovation activities of art students in colleges, and to mobilize their enthusiasm of various art instructors and art students, much attention must be paid to the cultivation of scientific innovation consciousness and ability. This requires colleges to provide relevant technological innovation conditions, environment and atmosphere. The construction of multiple innovation platforms is one of the main links to improve the implementation 
effect of scientific innovation activities for art college students. The construction effectiveness directly determines the starting point for these activities, and provides basis guarantee for improving the scientific innovation effect of art college students. Then, to construct a platform for cultivating scientific innovation abilities of art college students, the authors proposed to make preparations in the following four aspects: First, focus on the construction of arts teaching and research rooms, laboratories, and research bases, and strive to build national or provincial-level key ones with disciplinary or professional characteristics; secondly, pay attention to building a team of instructors with advanced professional literacy, and form a graded talent structure, instead of temporarily designating corresponding instructors according to the theme of scientific innovation, which can ensure continuity and expansion of the guidance for scientific innovation activities; thirdly, lay emphasis on the construction of scientific innovation activity groups of art college students by inspecting and selecting members, cultivate their professional literacy from multiple disciplines, perspectives, and fields, and then obtain art students with outstanding scientific innovation ability; fourth, focus on the integration of multiple means to improve their ability of scientific innovation. In addition to the classic forms of competition, it can be considered to use other forms such as art college students' academic communication report conferences, art education and training in famous teacher classrooms, and social needs-oriented industry-university-research integration, etc. Especially if the instructors undertake art research projects, they can encourage the college students to be more involved, and further improve their personal scientific innovation ability during the implementation of the projects.

\subsection{Starting with multi-theme to extend the professional perspective of art talents in scientific innovation}

In the past, the theme of scientific innovation activities for art college students was often determined for a specific discipline or specialty, which would affect the creativity of participators to a certain extent. In general, if the theme of innovation is strictly defined or restricted, it is difficult for art students who are not familiar about this category to become interested in this theme. In fact, with the rapid development of modern society, many disciplines and specialties are highly integrated. The expansion and connection between disciplines or specialties can often help to produce more innovative art works. For example, art design generally belongs to the academy of arts, and industrial engineering design is to the school of engineering. If the design theme is strictly limited to engineering, then college students in the academy of art often do not participate. Similarly, if the design theme is strictly limited to art, those in engineering may not. However, as we know, product modeling, graphic design, and product planning in engineering design are related to art design. Therefore, if the art design and engineering design are linked together, and the theme of scientific innovation is no longer limited to a certain aspect, then it will arouse the common interest of students both in engineering and art, so as to participate in scientific activities together and produce related works with stronger creativity and vitality. For this, the authors proposed to perform the multi-field, multi-discipline, and multi-specialty integration 
considering student interests and majors, and then to take the multi-theme integration as the entry point for scientific innovation of art students. This is conductive to expanding their professional perspective and professional accomplishment, and improving the comprehensive ability. In the integration process of multiple fields, disciplines, and specialties, laboratories can effectively establish the integration relationship between disciplines or specialties; while during the implementation, attention must be paid to determining the theme of scientific innovation, that is, the basis, application, or innovation type. In general, the same type of scientific innovation theme has better integration.

\subsection{Orienting towards social needs to enhance the social serviceability of scientific innovation}

The scientific innovation in colleges aims to improve the scientific innovation and practical application abilities of college students through the scientific innovation activities, and to effectively transform scientific knowledge and technology into social development. It can be seen that the goal of talents training in colleges has strong epochal character, orienting to the needs of social development. In the process of quality-oriented education, the cultivation of art students is an important part of the senior talent training, which plays a very important role in promoting the comprehensive quality of college students. Therefore, the cultivation of art students should be also based on social needs. In addition to the role of inheriting our traditional culture, it should be more in line with the development trend of today's society, and further enhance the social serviceability of scientific innovation for art college students. Oriented to the social needs, the training of art college students must be prepared in the following aspects: First, based on the needs of social development or corporate development, rationally and scientifically set goals for the construction and training of art students in colleges, to ensure the characteristics of the times and social serviceability; second, in addition to international cooperation and communication, the cultivation of art college students must be also integrated with the country's mainstream social ideology and consistent with the country's social culture and social spiritual civilization construction, so as to better promote social progress; third, apply social science and technology, and actively integrate the intelligent design theory, methods, means and techniques into the training of art students, which can enhance the integration of art industries and academic studies, and train the art talents through school-enterprise cooperation, thereby promoting the technological development with art, and deepening the artistic creation with scientific development.

\subsection{Using project management and performance rewards as a means to increase participation of art students in scientific innovation activities}

In order to enhance the overall scientific innovation quality of art students in colleges, one of the important links is to increase their participation in related innovation activities. Scientific innovation activities can better enhance the creative ability and practical ability of art students in colleges. They cannot only effectively consolidate 
their professional basic knowledge and professional ability, but also expanding the professional perspective and academic scope, which is conducive to promoting the multidisciplinary integration ability of art college students, and further enhancing the ability to transform their achievements and serving the society. Project management and performance rewards are two effective means and measures to increase the participation of art students in scientific innovation activities. Project management means to implement or develop the scientific innovation activities of art students based on scientific research projects, and then to perform management of these activities in the form of scientific research project management, i.e., fulfill all parts of scientific innovation project, ranging from the management system, project construction, project development, project approval, project inspection, to project conclusion etc. Besides, it is necessary to properly dividing the types and levels of scientific innovation projects for art students. Generally, the scientific innovation projects of art students can be divided into three categories: technological innovation, application innovation and theoretical innovation, as well as four levels such as international scientific innovation projects, national scientific innovation projects, provincial and ministerial scientific innovation projects, and other levels. Such division is conducive to the implementation of incentive measures. According to scientific innovation projects under different categories, the awards of college students in scientific innovation can be divided into international awards, national awards, provincial and ministerial awards and other awards levels, and each level can be subdivided into first-level rewards, second-level rewards, third-level rewards, etc. The awards are given to the person in charge of the scientific innovation project, the main project participants, and project supervisors. For the heads and the main participants of scientific innovation projects, the awards are closely related to their credits, talent title, bonuses, academic guarantee qualifications, and priority evaluation qualifications. For project supervisors, the awards of the scientific innovation projects are closely related to their annual workload, performance bonuses, talent titles, and qualifications for job titles. All these above can actively promote the scientific achievements of art students, improve the ideological and political awareness of college students and their supervisors, create a good atmosphere and environment, and attract the participation of more art students in the innovation activities, thereby enhancing their comprehensive quality.

\section{Performance Analysis for Scientific Innovation Model of Art Talents in Colleges}

\subsection{Selection of performance indicators}

The ultimate goal of the scientific innovation model is to effectively improve the comprehensive ability of art students in colleges. The implementation effect of this model can be reflected through the performance analysis for the training results of art students' comprehensive ability in the scientific innovation project. After survey research and inductive analysis, the author believes that the performance for the above can be measured in six aspects. The first is the cultivation of the professional literacy 
and professional ability of art college students, which is the basic condition for the creation of art works, denoted as A1; the second is the artistic innovation ability, denoted as A2, for only creative works of art have vitality; the third is the practical ability of artistic design, denoted as A3, because the creation of artistic works originates from practice and is higher than practice, and the artistic creation closer to the practice of social life is more sustainable; the fourth is the social serviceability of art college students, recorded as A4; the higher education aims to cultivate senior talents and ultimately promote the continuous progress of the society, while the scientific innovation model for cultivating art talents is an effective means to improve the comprehensive ability, which is more conducive to the cultivation of senior talents' social service capabilities; the fifth is the scientific achievements of art college students denoted as A5, which is the most basic manifestation of the implementation effect of the said model; the sixth is the transformation ability of scientific innovation, which is recorded as A6; only when scientific innovation is effectively applied to social practice can it be transformed into a driving force for social and technological progress, thereby generating social benefits and having real social value. Therefore, the scientific innovation transformation ability of art college students is an important part of their comprehensive ability.

\subsection{AHP-based weighting of performance indicators}

As described in the previous section, the indicator set A for analyzing the performance of comprehensive ability training of art students can be expressed as:

$$
\boldsymbol{A}=\left\{A_{1}, A_{2}, A_{3}, A_{4}, A_{5}, A_{6}\right\}
$$

Different performance indicators often have different effects on the results of performance analysis. In order to distinguish the importance degree of performance indicators, this paper uses the AHP method [16-18] to obtain weights of corresponding indicators.

First, consult the experts' opinions, and conduct a comparative analysis for the performance indicators in A in pairs using the 1-9 ratio scaling method [19-20], to obtain the judgment matrix $\mathrm{R}$ corresponding to the indicator set $\mathrm{A}$ :

$$
\boldsymbol{R}=\left[r_{i j}\right]_{6 x 6}=\left[\begin{array}{cccccc}
r_{11} & r_{12} & r_{13} & r_{14} & r_{15} & r_{16} \\
r_{21} & r_{22} & r_{23} & r_{24} & r_{25} & r_{26} \\
r_{31} & r_{32} & r_{33} & r_{34} & r_{35} & r_{36} \\
r_{41} & r_{42} & r_{43} & r_{44} & r_{45} & r_{46} \\
r_{51} & r_{52} & r_{53} & r_{54} & r_{55} & r_{56} \\
r_{61} & r_{62} & r_{63} & r_{64} & r_{65} & r_{66}
\end{array}\right]_{6 x 6}
$$


where, rij is the importance of the indicator Ai relative to the indicator $\mathrm{Aj}$, and satisfies $\frac{1}{9} \leq r_{i j} \leq 9, r_{i j} * r_{j i}=1$.

Then, acquire the feature vector $\mathrm{W}$ corresponding to the maximum feature root $\lambda \max$ of the judgment matrix $R$, and normalize it to obtain the weight sequence $\widetilde{\mathbf{W}}$ of the A:

$$
\boldsymbol{W}=\left\{w_{1}, w_{2}, w_{3}, w_{4}, w_{5}, w_{6}\right\}
$$

where, wi, $1 \leq \mathrm{i} \leq 6$ is the weight of the indicator $i$, and satisfies $0<$ wi $<1, \sum_{i=1}^{6} w_{i}=$ 0 .

Next, check the consistency of the judgment matrix R. Its calculation model is shown as:

$$
\left\{\begin{array}{l}
C I=\left(\lambda_{\max }-n\right) /(n-1) \\
C R=C I / R I
\end{array}\right.
$$

where, $\mathrm{CI}$ is the consistency index, $\mathrm{RI}$ is the random consistency index, and CR is the consistency ratio.

If satisfying $C R<0.10$, it indicates that the judgment matrix $R$ has good consistency, and the obtained index weights are valid; otherwise, the judgment matrix does not meet the consistency requirements, and the index weights need to be recalculated.

\subsection{Constructing a fuzzy information evaluation model based on performance indicators}

Due to certain fuzziness in the performance indicators, fuzzy information quantity [21-25] was used to measure the implementation effect of scientific innovation model for art students in colleges. For better statement, it's assumed that in the performance analysis process of this model, the fuzzy value of the i-th performance analysis object with respect to the $j$-th performance indicator is expressed as:

If the $\mathrm{j}$-th performance indicator is benefit-oriented, its standardized value is expressed as:

$$
U_{i j}=\left[u_{i j}^{a}, u_{i j}^{b}\right]=\left[v_{i j}^{a}, v_{i j}^{b}\right] / \max _{1 \leq i \leq n}\left(V_{i j}\right)
$$

If the $\mathrm{j}$-th performance indicator is cost-based, its normalized value is expressed as:

$$
U_{i j}=\left[u_{i j}^{a}, u_{i j}^{b}\right]=\min _{1 \leq i \leq n}\left(V_{i j}\right) /\left[v_{i j}^{L}, v_{i j}^{R}\right]
$$

After standardizing all performance s indicators, their optimal value sequence Uo is given as: 


$$
\left\{\begin{array}{l}
\boldsymbol{U}_{o}=\left\{u_{o 1}, \cdots, u_{o j}, \cdots, u_{o n}\right\} \\
u_{o j}=\max _{1 \leq i \leq n}\left(U_{i j}\right)=\left[\max _{1 \leq i \leq n}\left(u_{i j}^{a}\right), \max _{1 \leq i \leq n}\left(u_{i j}^{b}\right)\right]
\end{array}\right.
$$

Then, the fuzzy information quantity Iij of the $\mathrm{i}$-th performance analysis object with respect to the $j$-th performance indicator is expressed as

$$
I_{i j}=\log _{2} e^{-\sqrt{\frac{\left|u_{i j}^{a}-\max _{1 \leq i \leq n}\left(u_{i j}^{a}\right)\right|^{2}+\left|u_{i j}^{b}-\max _{1 \leq i \leq n}\left(u_{i j}^{b}\right)\right|^{2}}{2}}}
$$

It can be seen that if the value of the $j$-th performance indicator of the $i$ is closer to the optimal value, Iij shall be smaller. Therefore, considering the weights of the performance indicators on the implementation of the scientific innovation mode in various colleges, the weighted fuzzy information quantity $I_{i}^{*}$ can be given:

$$
I_{i}^{*}=\sum_{j=1}^{m} I_{i j}
$$

Thus, an optimal model for evaluating the model's performance in colleges is established, that is, if it satisfies:

$$
I_{k}^{*}=\min \left(I_{1}^{*}, \cdots, I_{i}^{*}, \cdots, I_{n}\right), 1 \leq k \leq n
$$

Then, the k-th performance analysis object has the optimal scientific innovation model for art students

\section{Conclusion}

The authors firstly identified the key problems in the current scientific innovation model for art talent training in colleges, and then proposed some strategies to improve this model from different aspects such as construction of innovation platforms, integration of multiple scientific innovation themes, social demand-orientedness for scientific innovation, and project management and performance rewards. Based on this, a fuzzy information evaluation model was established based on the weighted performance indicators in order to evaluate the scientific innovation model more effectively. This study shall provide strong supports to the scientific innovation of art talents in colleges, and has significant application value for promoting their comprehensive quality. 


\section{Acknowledgment}

1. Research on the Contemporary Value of Red Classical Oil Painting in the Context of New Age (Ranked 4th), Humanities and Social Sciences Research Project of Ministry of Education's;

2. Intangible Cultural Heritage-Research on the Popularization of Face Painting Art in Society, Art Science Planning Project of Heilongjiang Province (No. 2016D078);

3. Study on the Inheritance and Innovation of Han Dynasty Stone Portrait Art in Contemporary Oil Painting Creation (ZD201906173), Key Project of Shandong Science and Technology in 2019;

4. Campus Cultural and Creative Products Based on Heilongjiang Traditional Folk Art in 2015, Provincial Department of Culture 2015-2017.

\section{$7 \quad$ References}

[1] Cai, R., Wang, Z. L., Yue, T. L., Yuan, Y. H., Tai, H., Yan, Y. (2019). Exploration and implementation of undergraduate innovation projects under the background of "Double First-Class" construction: Taking college of food science and engineering of Northwest A\&F University as an example. Journal of Chengdu Normal University, 35(9): 1-5. https://doi.org/ 10.3969/j.issn.2095-5642.2019.09.001.

[2] Cadenas, G. A., Cantú, E. A., Lynn, N., Spence, T., Ruth, A. (2020). A programmatic intervention to promote entrepreneurial self-efficacy, critical behavior, and technology readiness among underrepresented college students. Journal of Vocational Behavior, 116: 1-11. https://doi.org/10.1016/j.jvb.2019.103350.

[3] Wang, J. C., Li, F., Tang, S. C. (2019). The current situation of scientific and technological innovation of college students and the strategies to improve the effect of scientific and technological innovation. Chuangxin Yu Chuangye Jiaoyu, 10(6): 79-82.

[4] Amornkitpinyo, T., Wannapiroon, P. (2015). Causal relationship model of the technology acceptance process of learning innovation in the $21^{\mathrm{ST}}$ century for graduate students. Procedia-Social and Behavioral Sciences, 174: 2090-2095. https://doi.org/10.1016/j.sbs pro.2015.02.006

[5] Li, W. (2017). Artistic persistence and technological innovation of "hand painting + 3D" Disney animation film. Film Review, (24): 97-99. https://doi.org/10.16583/j.cnki.521014/j.2017.24.031.

[6] Sawyer, R. K. (2019). The role of failure in learning how to create in art and design. Thinking Skills and Creativity, 33: 1-10. https://doi.org/10.1016/j.tsc.2018.08.002.

[7] Zeng, L. H. (2016). Combining humanities with science and technology to cultivate innovative talents--Taking the cultivation of art design talents under the condition of information technology as an example. Chinese University Technology Transfer, (12): 5254. https://doi.org/10.16209/j.cnki.cust.2016.12.015.

[8] Yong, W. M. (2017). Technological innovation and artistic aesthetics. Art Criticism, (6): 50. https://doi.org/ 10.16364/j.cnki.cn11-4907/j.2017.06.009.

[9] Lu, N. (2014). An analysis of the cultivation of innovative art design talents in colleges and universities. Art Education Research, (3): 152-153. https://doi.org/CNKI:SUN: MSJY.0.2014-03-100. 
[10] Cong, L., Zhu, Z. Y., Qu, L. W., Li, D. D. (2017). The combination of technology and art - Taking Northeast University as an example to explore the innovative design of the combination of wechat public platform and campus culture. Packaging World, (3): 67-69. http://dx.doi.org/10.13337/j.cnki.packaging.world.2017.03.020.

[11] Mahdi, R., Sukarman, S. S., Yok, M. C. K. (2015). Fostering creativity through innovation engagement in science and technology education: Case study of universiti teknologi MARA students. Procedia-Social and Behavioral Sciences, 167: 256-260. https://doi.org/10.1016/j.sbspro.2014.12.671.

[12] Hashemi, H., Haghighat, J., Eslami, M. (2020). Performance analysis of relay-aided millimeter-wave communications with optimal and suboptimal combining at destination. Physical Communication, 39: 1-12. https://doi.org/10.1016/j.phycom.2019.100991.

[13] Senderovich, A., Weidlich, M., Gal, A. (2019). Context-aware temporal network representation of event logs: Model and methods for process performance analysis. Information Systems, 84: 240-254. https://doi.org/10.1016/j.is.2019.04.004.

[14] Pinheiro, E., Bandeiras, F., Gomes, M., Coelho, P., Fernandes, J. (2019). Performance analysis of wind generators and PV systems in industrial small-scale applications. Renewable and Sustainable Energy Reviews, 110: 392-401. https://doi.org/10.1016/j.rser. 2019.04.074.

[15] Tronchin, L., Manfren, M., James, P. A. B. (2018). Linking design and operation performance analysis through model calibration: Parametric assessment on a Passive House building. Energy, 165: 26-40. https://doi.org/10.1016/j.energy.2018.09.037.

[16] Wang, W.X. (2019). Site selection of fire stations in cities based on geographic information system (GIS) and fuzzy analytic hierarchy process (FAHP). Ingénierie des Systèmes d'Information, 24(6): 619-626. https://doi.org/10.18280/isi.240609

[17] Piri, I., Moosavi, M., Taheri, A. Z., Alipur, H., Shojaei, S., Mousavi, S. A. (2019). The spatial assessment of suitable areas for medicinal species of Astragalus (Astragalus hypsogeton Bunge) using the Analytic Hierarchy Process (AHP) and Geographic Information System (GIS). The Egyptian Journal of Remote Sensing and Space Science, 22(2): 193-201. https://doi.org/10.1016/j.ejrs.2018.02.003.

[18] Barić, D., Pižeta, F. (2018). An AHP model for level crossing design. International Journal of Safety and Security Engineering, 8(1): 65-76. https://doi.org/10.2495/safe-v8-n1-65-76

[19] Salvia, A. L., Brandli, L. L., Filho, W. L., Kalil, R. M. L. (2019). An analysis of the applications of Analytic Hierarchy Process (AHP) for selection of energy efficiency practices in public lighting in a sample of Brazilian cities. Energy Policy, 132: 854-864. https://doi.org/10.1016/j.enpol.2019.06.021.

[20] Abrams, W., Ghoneim, E., Shew, R., LaMaskin, T., Al-Bloushi, K., Hussein, S., AbuBakr, M., Al-Mulla, E., Al-Awar, M., El-Baz, F. (2018). Delineation of groundwater potential (GWP) in the northern United Arab Emirates and Oman using geospatial technologies in conjunction with Simple Additive Weight (SAW), Analytical Hierarchy Process (AHP), and Probabilistic Frequency Ratio (PFR) techniques. Journal of Arid Environments, 2018, 157: 77-96. https://doi.org/10.1016/j.jaridenv.2018.05.005.

[21] Balamash, A., Pedrycz, W., Al-Hmouz, R., Morfeq, A. (2015). An expansion of fuzzy information granules through successive refinements of their information content and their use to system modeling. Expert Systems with Applications, 42(6): 2985-2997. https://doi. org/10.1016/j.eswa.2014.11.027.

[22] Seiti, H., Hafezalkotob, A., Najafi, S. E., Khalaj, M. (2019). Developing a novel risk-based MCDM approach based on D numbers and fuzzy information axiom and its applications in preventive maintenance planning. Applied Soft Computing, 82: 1-17. https://doi.org/10.10 16/j.asoc.2019.105559. 
[23] Marwan, H., Ali, A. (2019). Experts' consensus to identify elements of career management competencies in Work-Based Learning (WBL) program using fuzzy delphi analysis. International Journal of Emerging Technologies in Learning, 14(20): 73-86. https://doi.org/ $\underline{10.3991 / i j e t . v 14 i 20.11461}$

[24] Ebrahiminejad, M., Shakeri, E., Ardeshir, A., Zarandi, M.H.F. (2018). An object-oriented model for construction method selection in buildings using fuzzy information. Energy and Buildings 178: 228-241. https://doi.org/10.1016/j.enbuild.2018.08.002

[25] Kahraman, C., Onar, S.C., Cebi, S., Oztaysi, B. (2017). Extension of information axiom from ordinary to intuitionistic fuzzy sets: An application to search algorithm se-lection. Computers \& Industrial Engineering, 105: 348-361. https://doi.org/10.1016/j.cie.2016.12.0 $\underline{12}$

\section{Author}

Fanwen Kong, a graduate from Shanghai Theater Academy. He works on painting practice and teaching in the Art College of Shandong University (Weihai). He is specialized in oil painting, lacquer painting, art education and teaching management, and has published several core papers.

Article submitted 2020-04-13. Resubmitted 2020-05-26. Final acceptance 2020-05-27. Final version published as submitted by the authors. 